\title{
A Contextual Approach to Teaching Sustainability
}

\section{Dr. Robert L. Nagel, James Madison University}

Dr. Robert Nagel is an Assistant Professor in the Department of Engineering at James Madison University. Dr. Nagel joined the James Madison University after completing his Ph.D. in mechanical engineering at Oregon State University. He has a B.S. from Trine University and a M.S. from the Missouri University of Science and Technology, both in mechanical engineering. Since joining James Madison University, Nagel has helped to develop and teach the six course engineering design sequence which represents the spine of the curriculum for the Department of Engineering. The research and teaching interests of Dr. Nagel tend to revolve around engineering design and engineering design education, and in particular, the design conceptualization phase of the design process. He has performed research with the US Army Chemical Corps, General Motors Research and Development Center, and the US Air Force Academy, and he has received grants from the NSF, the EPA, and General Motors Corporation.

\section{Dr. Elise Barrella, James Madison University}

Dr. Elise Barrella is an Assistant Professor of Engineering at James Madison University, who focuses teaching, scholarship, service, and student mentoring on transportation systems, sustainability, and engineering design. Dr. Barrella completed her Ph.D. in Civil Engineering at Georgia Tech where she conducted research in transportation and sustainability as part of the Infrastructure Research Group (IRG). Dr. Barrella has investigated best practices in engineering education since 2003 (at Bucknell University) and began collaborating on sustainable engineering design research while at Georgia Tech. She is currently engaged in course development and instruction for the junior design sequence and the freshman design experience, along with coordinating junior capstone at JMU. In addition to the Ph.D. in Civil Engineering, Dr. Barrella holds a Master of City and Regional Planning (Transportation) from Georgia Institute of Technology and a B.S. in Civil Engineering from Bucknell University.

\section{Dr. Eric C Pappas, James Madison University}

Eric Pappas is Professor of Integrated Science and Technology at James Madison University and formerly a faculty member in the College of Engineering at Virginia Tech (1993-2003).

\section{Dr. Jesse Pappas, James Madison University}

Jesse Pappas studied self-insight, intentional self-development, and the role of emotion in self-perception at University of Virginia, where he received a Ph.D. in social psychology in 2012. His dissertation project involved adapting established professional development tools to facilitate the personal and academic success of college students. Jesse currently serves as Assessment Director and Assistant Professor at Future Generations Graduate School. As a research fellow in the School of Engineering at James Madison University, he works to equip future scientists and engineers with the personal and social savvy they need to thrive in today's complex professional environments. 


\title{
A Contextual Approach to Teaching Sustainability
}

\begin{abstract}
The goal of this project is to research sustainability across contexts (environmental, economic, social, technical, and individual) in order to determine the best methodologies for teaching these contexts across academic disciplines (in our case: engineering, integrated science and technology, psychology, education, English, and communication studies). We are working to determine the most effective ways in which to assess these methodologies using behaviors as educational outcomes. This research has focused on creating cognitive dissonance by demonstrating to students the difference between their stated values and behaviors across sustainability contexts. Key studies have focused primarily on individual sustainability, but smaller catalyst studies have also focused on the self-knowledge that informs decision making and problem solving, cultivating mindfulness as an approach to sustainable living, understanding the self as a sustainable system, promoting sustainable student and reader behaviors in literature, and changes in metacognitive strategies and exam performance by attribution status (among others). The final deliverable will be the first iteration of a low-cost scalable and transferable global model for instructional integration that will allow students and faculty to engage in meaningful and intentional self-development of behaviors in specific sustainability content areas.
\end{abstract}

\section{Introduction}

Two tragic characteristics tend to characterize human behavior: 1) our inability to employ a systems approach for understanding the world around us, as well as ourselves; and 2) our failure to demonstrate behavior that is aligned with our values. These factors tend to result in individuals who are often unable to direct their own personal growth and professional development.

The central goal of this research is to help students understand and employ intentional selfdevelopment strategies in a variety of contexts. What are the skills and reasoning that underlie an individual's ability to intentionally direct his or her own personal and professional development - and how can we teach these skills and behaviors? Systems theory is at the core of this methodology as is an understanding of sustainability across contexts (environmental, economic, social, technical, and individual). Together these provide a foundation that leads to greater understanding of the world as well as the ability to demonstrate effective intentional selfdevelopment skills. The wide variety of research projects conducted under this grant have resulted in the development of successful pedagogies that lead students to effective behavioral changes, ones that support intentional self-development.

In this research, we have focused on creating cognitive dissonance between students' stated values and subsequent behaviors across sustainability contexts. Using a variety of settings, tools, and methodologies, we have focused primarily on individual sustainability (emotional, social, physical, philosophical, and intellectual) and the self-knowledge that informs professional selfminded engineers, enhances decision making and problem solving in engineering and the sciences, cultivates mindfulness as an approach to sustainable living, and promotes understanding of the self as a sustainable system. 
This paper is based on work completed under an NSF Engineering Education Grant \#1158728: Research into Instructional Content and Methodologies for Teaching Sustainability. We have found that our research in a variety of settings and disciplines has yielded support for our hypothesis that creating cognitive dissonance between students' values and behaviors strongly motivates them to change their behaviors in the direction of more sustainable and thoughtful action.

\section{Literature Review}

We do not consider environmentalism to be the central context in sustainability. This departure from convention allows students to recognize that sustainability is a complex system; that everything is connected to everything else, and that a change in one context in sustainability will result in unpredictable changes in the other contexts. A systems approach to sustainability includes the following contexts: economic, environmental, social, technical, and individual. The approach (and philosophy) embraced in our research places social sustainability - and by obvious connection, individual sustainability—as the central contexts.

\subsection{Individual Sustainability}

An important context missing from most discussions of sustainability, especially within academia (or society in general), is individual sustainability. Living a sustainable lifestyle includes creating harmony, interconnection, and relatively high levels of awareness in one's values, thoughts, and behaviors, as well as maintaining an increasing control over one's physical, emotional, social, philosophical/spiritual, and intellectual life. ${ }^{1}$ The general skills that lead to individual sustainability are awareness, motivation, and the ability to engage in intentional self-development.

Individual sustainability is likely the most important factor influencing the success of activities in the other four contexts as it is one's individual behavior that creates the foundation for action in social, economic, and environmental sustainability and potentially guides our ability to work with one another to solve problems and make life-affirming decisions. For this reason, learning about sustainability should start with understanding individual sustainability in the following contexts: physical, cognitive, emotional, social, and philosophical.

Successful attempts at maintaining meaningful individual sustainability are dependent upon one's ability to change intentionally. Such growth may be difficult for some, and the challenges to individual development may be hindered by personal, career, family, and psychological issues, as well as a dysfunctional relationship with time or technology. ${ }^{2}$ Some psychologists, like Maslow $^{3}$ and Rogers, ${ }^{4}$ as well as engineers Adams ${ }^{5}$ and Petroski, ${ }^{6}$ suggest that barriers to growth are related to a variety of personal limitations or insecurities. Bigda-Peyton ${ }^{7}$ suggests that "humans have inherent [psychological] tendencies to destroy and use up" and that "harmful overconsumption occurs when psychic structures dominated by destructive instincts succeed in overpowering life-sustaining impulses" (p. 264). Academia often deemphasizes such personal topics, yet it is quite clear that little meaningful and lasting societal change will take place until individuals understand and address the nature of sustainability on this deeply personal level. 


\subsection{Theories of Intentional Self-Development and Intentional Change}

Several decades ago, Rogers ${ }^{8}$ considered the motivation behind intentional self-development: "...to actualize, maintain, and enhance the experiencing organism" (p. 487). Maslow also discussed intentional self-development - "self-actualization" - as the key to individual growth and change although his approach was generally more abstract than those noted here. The contributions of Brandtstädter's ${ }^{9}$ Development Systems Theory are central to the body of research on individual change, and he maintained that individuals are both the products and producers of their own self-development - that our motivations guide and shape our personal development. Baltes and Baltes ${ }^{10}$ and Freund et al. ${ }^{11}$ noted that, through the consequences of intentional actions, individuals develop guides (motivations, intentions) for further goal-oriented action; and, hence, this "action" becomes the driver for change.

Brandtstädter ${ }^{12}$ suggested that "beliefs related to the control of personal development deeply influence the ways in which individuals experience, and try to manage, their development in different phases and areas of life" (p. 198). Others, including Rotter, ${ }^{13}$ Schultz and Heckhausen ${ }^{14}$ and Morf and Horvath ${ }^{15}$ stressed intentional self-development as a means for improving both cognitive and affective abilities.

Gestsdottir and Lerner ${ }^{16}$ referred to these developmental processes as "intentional selfregulation"- actions aimed towards harmonizing personal goals in order to enhance selfdevelopment. This is relevant to our subsequent and current studies since successful intentional changes were entirely dependent upon the students' learning and demonstrating increasing control over their behaviors, and selecting desirable and achievable goals. Selecting such goals and identifying desirable behaviors, according to Baltes, ${ }^{17}$ reduces the possibility of unsuccessful results and increases the likelihood of developing methods that lead to desired outcomes. According to Brandtstädter ${ }^{12}$ reflective thought and intentional control of behaviors, especially strategies employed to make progress towards achieving a goal, are central processes that help create the desired change in behavior.

\subsection{Applications of Intentional Self-Development}

Maslow $^{3}$ described the "self as a project" (p. 12), terminology he likely lifted from Jean-Paul Sartre, in which intentional change processes, along with effective decision making, allowed the increasingly self-actualized individual to "...make himself into anything he decided to be" ( $p$.

12). Rogers ${ }^{4,18}$ centered much of his philosophy and practical methodology on change processes as a method for seeking knowledge, developing learning skills, and living as "individuals in process" (p. 105). ${ }^{18}$

Specific approaches to intentional self-development have taken several forms, and Brandtstädter's ${ }^{9}$ four principle components of self-development have influenced most recent approaches. These stages include 1) the ability to control one's everyday behavior, 2) the development of a structured self-concept, 3) the ability to evaluate and correct behavior, and 4) the integration of these processes into a stable identity. ${ }^{9}$ Among other successful structured behavioral approaches to intentional self-development, Prochaska and Velicer ${ }^{19}$ developed the Transtheoretical Model of Health Behavior Change, which notes five stages of the change 
process: pre-contemplation, contemplation, preparation, action, and maintenance, each of which is dependent upon intentional control of behavior (self-regulation) and reflection (contemplation). The stages in Prochaska and Velicer, as well as those in Brandtstädter, represent a closely monitored and structured approach that approximates the process the authors used in past research focused on slow change. ${ }^{20}$ Structured approaches to behavioral change require individuals to create a workable plan to be executed over a pre-determined period of time, to monitor progress, to reflect upon and evaluate progress, and to adjust the plan according to the relative successes or failures of the plan. ${ }^{21,22}$

\subsection{Cognitive Dissonance}

Our experimental studies over the last three years, as well as our increasingly formal studies, have focused on cognitive dissonance as a motivation for change. Cognitive dissonance is a psychological situation arising from inconsistent knowledge, which can be reduced or eliminated only by decreasing the inconsistency. ${ }^{23}$ Cognitive dissonance is largely about the resistance to change of cognitions and the degree to which dissonant factors conflict.

Behavior, because of its naturally reinforcing nature, is at the center of resistance to change as well as imperative to reducing or eliminating cognitive dissonance. In his original theory, Festinger $^{23}$ outlines three factors central to creating cognitive dissonance in an individual: 1) having to choose between alternatives, 2) the existence of a behavior one might normally avoid, and 3 ) the occurrence of new information. Brehm and Cohen ${ }^{24}$ noted that behavioral commitment was not simply a central factor in reducing dissonance, but a necessary condition in the dissonance reduction process. According to Wicklund and Brehm, "dissonance reduction is accomplished by changing the behavioral element" (p. 5). The authors further noted that dissonance reduction in the form of active decisions or changed behaviors tends to persist, in some form or other, even years following the event since maintaining such a cognitive state was not subject to continued motivation. ${ }^{25}$

Harmon-Jones et al.'s ${ }^{26}$ action-oriented model, which posits that cognitive discrepancies generate dissonance because they interfere with efficient belief-consistent actions, also is compatible with the fundamental premises of dissonance, as is recent research that demonstrates vicarious dissonance arousal. ${ }^{27,28}$

\section{Methods and Tools}

The research performed under the NSF Engineering Education Grant \#1158728: Research into Instructional Content and Methodologies for Teaching Sustainability has been divided into two key phases. During the first phase of the research, a multi-disciplinary team of researchers representing engineering, science and technology studies, social sciences, education, and humanities worked together performing catalyst studies to explore and identify effective crossdisciplinary methodologies for integrating instruction focused on aligning students' personal values and behaviors in sustainability into existing course materials. Following these catalyst studies, larger case studies have focused on assessing scalable and transferable models for instructional integration using the methods and tools identified during the catalyst studies as 
those most effective at fostering alignment of students' personal values and behaviors. Specifically, in this research, we define values and behaviors as follows.

- Values are the beliefs in the significance and meaning of objects, qualities, or human behaviors. Values may be personal and individually held or guided by community/cultural, governmental, or corporate norms.

- Behaviors are the competencies students can demonstrate - rather than simply the acquisition of knowledge of, or attitudes towards, a particular topic. Individual behaviors are one's actions and decisions across sustainability domains in all decision making contexts.

Three key methodologies provide the underlying foundation for research performed under this grant. First is a pedagogical approach to sustainability that employs systems theory stressing that the interrelationship of factors in a unified system depend upon the unpredictable nature of the relationship of individual factors (emotional, social, physical, philosophical, and intellectual). In other words, sustainability must begin with the individual. Second, an individual's demonstrated behaviors following an educational intervention are a more effective measure of learning than are affirmation of learned skills and knowledge or new attitudes and goals. Third, one's values provide an individual with the necessary principle guiding force for self-development and intentional individual change when confronted with disparities between stated values and behaviors. Through recognition that change must begin with one's self and a heightened selfawareness of one's values and behaviors, students may engage in meaningful and intentional self-development.

Through catalyst studies these three methodologies have come together into the following generalizable pedagogical approach, as shown in Figure 1. First, students learn about systems theory and individual sustainability through class lectures, discussions, and readings.

Understanding and change are assigned as out-of-class assignments and do not require any in class time for implementation. During the understand phase, students affirm their values (typically through survey instruments) and describe their personal behaviors. In the change phase, cognitive dissonance is developed to motivate intentional self-development. An action plan guides students' plans for change, and formal reflections and evaluations help students monitor progress.

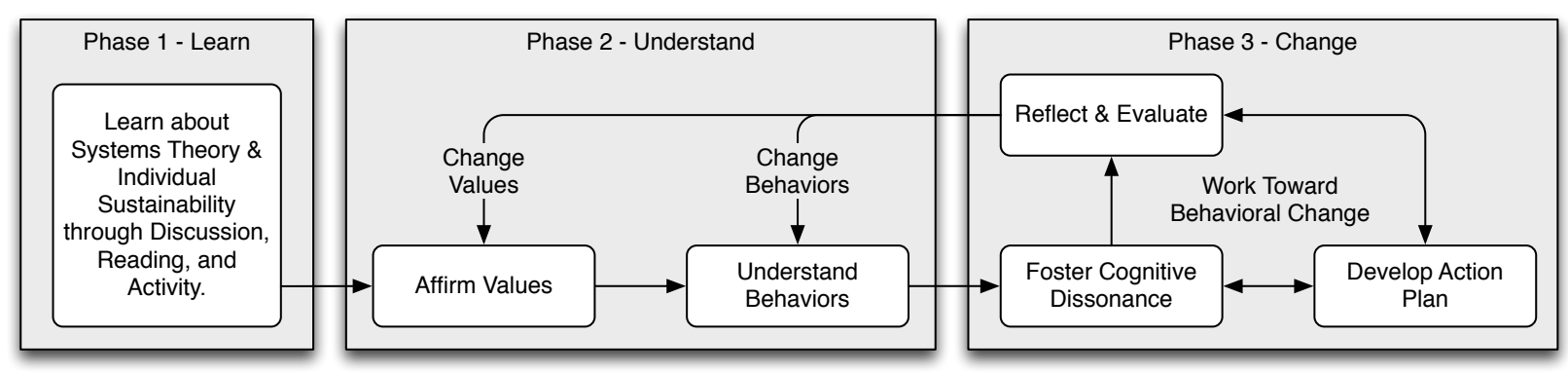

Figure 1: Pedagogical Approach 
Each of the tools and methods applied through catalyst and case studies are defined as follows:

- Value Affirmation: Value affirmation is the process by which an individual asserts a belief in a particular value, and the assertion may be either explicit or implicit. When explicit, value affirmation typically occurs through a survey instrument containing value statements, and individuals rate their values on a Likert scale. When implicit, value affirmation occurs through the assertion of desirable or ideal behaviors of an individual or population (e.g., an ideal professional engineer would be ethical in all business dealings).

- Behavior Understanding: Behavior understanding is the process by which individuals identify their current actions or decisions with respect to a particular domain. In this research, behavior is always explicit taking the form of a survey instrument, and individuals rate their behaviors (as listed in the survey instrument) on a Likert scale. For example, an individual might rate the behavior, "When making contractual decisions, I always allow bribes to sway my decision making," highly as in that he or she agrees strongly with this behavior.

- Cognitive Dissonance: Our approach to research into cognitive dissonance is behavioral but with the recognition that cognitive and behavioral factors are largely interconnected and tend to function on complementary terms. Our research addresses cognitive dissonance that is intentionally introduced into a setting, not the dissonance that occurs in everyday life or comes to our attention through typical life events. As well, our approach to cognitive dissonance focuses on the alignment of values and behaviors in our students, in that students' stated values are often in conflict with their demonstrated behaviors. For example, cognitive dissonance may be recognized by an individual if he or she rates strongly in agreement that "an ideal professional engineer would be ethical in all business dealings," yet that same individual rates highly in agreement that "when making contractual decisions, I always allow bribes to sway my decision making."

- Intentional Self-Development: The process by which individuals work toward aligning their ideal behaviors or values with their actual behaviors. Intentional self-development may refer to either fast or slow change processes.

- Concept Maps: Concept maps (or cmaps) are graphical tools for organizing and presenting knowledge. A cmap consists of a central topic that branches off into different hierarchies by identifying related concepts and connecting them with linking lines and phrases. Cross-links (consisting of a line and descriptive phrase) are used to connect concepts across two or more hierarchies. The use of cmaps to capture the structure and content of student knowledge ${ }^{29}$ is supported by cognitive psychological research in the area of semantic memory, which refers to an organized database of concept-based knowledge. ${ }^{30}$ Concept maps can be used as both an instructional and assessment tool, and in this research are used to capture student conceptualizations of the five sustainability concepts. 
- Reflection: Per Boyd and Fales, ${ }^{31}$ reflection may be defined as "the process of creating and clarifying the meaning of experience (present or past) in terms of self (self in relation to self and self in relation to the world)" (p. 101). Through a review of literature by Van Manen, Mezirow, Boyd and Fales, Goodman, Boud, and Schon on reflective processes, Atkins and Murphy ${ }^{32}$ deduced that the process of reflection can most simply be summarized by three phases. During phase one, "an awareness of uncomfortable feelings and thoughts" initiates the reflective process (p. 1189). ${ }^{32}$ During phase two, one performs "a critical analysis of the situation, which is constructive and involves examination of feelings and knowledge" (p. 1189). ${ }^{32}$ During the third phase, one develops a "new perspective" on the issues which arose the initial discomfort (p. 1190). ${ }^{32}$ This new perspective may lead to or may perpetuate intentional self-development efforts or may result in changes to one's values or behaviors, hence the two-way connection from Reflect \& Evaluate in Figure 1 to Develop Action Plan and the one-way arrows from Reflect \& Evaluate to both Affirm Values and Understand Behaviors.

\section{Research Studies}

Per the project methodology, this research project was divided into two phases. Catalyst studies carried out by a multi-disciplinary team of researchers were focused on applying the generalized pedagogical approach across university disciplines. Catalyst studies informed larger and more focused case studies which have been completed in engineering as well as science and technology studies courses. This section provides an overview of catalyst studies as well as descriptions of three case studies.

\subsection{Catalyst Studies}

Catalyst studies were carried out in engineering, science and technology studies, social sciences, education, and humanities courses and represented a variety of different types of studies with the goal of exploring the application of intentional self-development based on cognitive dissonance between values and behaviors. An overview of these catalyst studies follows. It should be noted that not all of the catalyst studies resulted in publishable results, but instead they informed the later case studies.

- The Self-knowledge that Informs Decision Making and Problem Solving. Empirical observations of engineering students working with clients and in teams has led us to realize that a higher communication barrier, and the more distinct the differences between each student as well as the client, the more likely students are to disengage from the project and their teams. The overarching goal of this catalyst study was to make students aware of this dissonance and encourage them to balance more effectively the selfknowledge that informs decision making and problem solving. ${ }^{33}$ Through this study, students worked closely with a client with a disability (as the students do every semester in this course) and reflected frequently on the experience. New course modules (added to subsequent course offerings) were developed to help students through dissonance noted in their personal reflections. 
- Cultivating Mindfulness as an Approach to Sustainable Learning. This study sought to help students in a integrated science and technology course cultivate mindfulness as a vehicle to promote more sustainable learning. Students with sustainable learning habits possesses the ability to perform and succeed academically, not just with respect to intentional regulation and cognitive development, but also with respect to the quality of their emotional well-being as it pertains to the values and conditions that promote continued prosperity and growth.

- Understanding the Self as a Sustainable System. Students in an writing and rhetoric course explore the concept of systems theory through creative and reflective writings. Students write about themselves (both abstractly and directly) as interlocking "systems" determined by the five contexts in individual sustainability (emotional, intellectual, social, physical, philosophical). Students visually inter-animate these five contexts in individual sustainability to show how balanced they feel at the moment. The goal is to translate ways individuals may already think about their identities within the contexts and definitions of Individual Sustainability.

- Sustainable Personality. Students in an integrated science and technology course experience cognitive dissonance when they realize their behaviors related to sustainability do not reflect their values. We expected students would work to align their behaviors with their values. Three primary objectives are meant to encourage students to change their everyday behaviors: 1) to facilitate individual sustainability awareness; 2) to study the cognitive dissonance that occurs when students realize that their behaviors related to physical, emotional, social, economic, and intellectual sustainability do not align with their values; and 3) to determine, when faced with this dissonance, if and how students are motivated to individual behavior change. ${ }^{34}$ Student reflections indicated positive changes in relationships, study behaviors, time use, and relationship with technology as well as an improved sense of personal integrity and self-esteem, and decreased stress and anxiety. ${ }^{34}$

- Role Behavior in Groups. The goal of this research is to assist students in improving their academic life (individual sustainability) by asking them to reflect on their values, thoughts, and behaviors related to small group problem solving. After engaging in selfreflection, students engaged in a series of small group activities with each student's teammates providing a ranking of each of their peer's behavior. ${ }^{35,36}$ Student reflections indicated that cognitive dissonance was created as a result of course modules. A set of role behaviors and values related to groups was generated as a part of this study. This study was completed with students in an engineering course as well as with students in a communication studies course.

- Changes in Metacognitive Strategies and Exam Performance by Attribution Status. This study explored a metacognitive intervention to encourage generalizable changes in student attribution styles as they pertain to academic effort, strategy, and achievement in a general education psychology course. We hypothesized that confronting students with their planned behavior and actual results might encourage cognitive dissonance resulting in a stable adjustment of attribution style and academic performance. It was further 
hypothesized that the effect may differ by baseline attribution style. While cognitive dissonance was noted, student performance did not change, indicating that there are other factors influencing students academic effort, strategy, and achievement in this general education course.

\subsection{Case Studies}

In this paper, three of the larger case studies that followed the initial catalyst studies are highlighted. The three case students are (1) Sustainable Personality with Personality Pad, (2) Fast Change: Teaching Intentional Self-development, and (3) Cognitive Dissonance and Formation of Professional Engineers. Descriptions of these case studies follow.

Research Study \#1: Sustainable Personality with Personality Pad. The general objective of this research is to determine how an interactive website (PersonalityPad.org) providing multisource feedback on personality motivates students to change their behaviors or values, or to align their behaviors and values. PersonalityPad.org is a website whose goal is to foster intentional self-development in the area of individual sustainability. Personality Pad automates the process of $360^{\circ}$ evaluation, also known as multi-source feedback, allowing an individual to experience a process leading to self-discovery and personal growth. ${ }^{37}$

The purpose of this study was to determine which group of students - first year science and technology students (in a class focused on individual change), or upper-level psychology students (in a class unrelated to individual change) — would report greater personal changes following using Personality Pad.

In this study, four hundred students in two classes, a general education science and technology class and an upper-level psychology class, were given a 50-item multi-source feedback online survey, Sustainable Personality (on PersonalityPad.org); this survey assessed individual sustainability in the following contexts: emotional, social, physical, economic, and intellectual. Following a post-test, reflective essays, and a later follow-up survey, results revealed that many students increased their awareness of the topic of individual sustainability and reported changes in their behaviors and values. ${ }^{1}$

The science and technology students reported slightly higher levels of increased awareness than the psychology students $(100 \%$ vs. $94 \%) .{ }^{1}$ While more science and technology students reported greater motivation toward behavioral changes than the psychology students ( $96 \%$ vs. $60 \%$ ) or engaging in actual behavioral changes (66\% vs. 50\%), both groups had substantial numbers making personal changes. ${ }^{1}$ Fewer students report making changes in values due to their interaction with the website and survey. ${ }^{1}$ Over $73 \%$ of science and technology students and $40 \%$ of psychology students reported motivation toward making some changes in values, and $41 \%$ vs. $22 \%$ reporting actual changes in values. ${ }^{1}$

The final issue, whether the survey process helped students align their behaviors with their values, is the most important one and, as well, the most relative. Science and technology students reported $90 \%$ agreement, and psychology students reported $48 \%$ agreement. ${ }^{1}$ While this 
particular question did not require students to explain the degree of their "improved alignments," these numbers are encouraging whatever the case.

Our results in this study are encouraging, and we continue to research these effects. If students' self-reports are to be believed to any degree, this study has yielded measureable changes in personal awareness, values, and behavioral change. Most importantly, because students experienced some success in these improved behaviors (that is, behaviors aligned with their values), their narrative responses reflected an improved sense of personal integrity and selfesteem. It is true here, perhaps, that if a change in one's behaviors improves daily life, then those behaviors tend to be repeated and perhaps become a personality characteristic. ${ }^{2}$

Case Study \#2: Fast Change: Teaching Intentional Self-development. This experimental study using cognitive dissonance as a tool for self-development is a departure from our established research in that we are experimenting with producing lasting personality/behavioral change in one week. ${ }^{38}$

In this study, conducted in Fall 2014, the motivation for students to make rapid intentional changes is cognitive dissonance, ${ }^{23}$ most specifically between their everyday values and behaviors. Twenty-five upper-class students took part in the study as a project in a senior-level special study social psychology course: Sustainable Personality. Briefly, students wrote narratives meant to discover and examine the differences between their "real self" and "ideal self." Following a written analysis of cognitive dissonance in these essays, students were required to be their "ideal self" in every situation for a week. All students submitted electronic journal entries to their teaching assistant each night and took two surveys: one following the experimental week, and another at the end of the semester. ${ }^{23}$

The surprisingly encouraging results in this study, from focus groups, narratives, and two surveys, tend to support our hypothesis that when students recognize that their behaviors do not match their values, they engage in rapid positive personal change. ${ }^{23}$ Two reasons stated by many students as to why they felt motivated to make changes is that the change processes were "easier than they expected" and "made them feel good about themselves." Additionally, it appeared that, confronted with this cognitive dissonance, many students were highly motivated by wanting to live a life characterized by authenticity and integrity. Results will be published in a forthcoming publication.

Case Study \#3: Cognitive Dissonance and Formation of Professional Engineers. Beginning in Fall 2014, we have focused on engineering students' conceptualizations of the five contexts of sustainability (environmental, economic, social, individual, and technical) and used a revised Sustainable Personality survey to ascertain in which areas students identify the greatest dissonance and use that self-identified dissonance to direct change. In Fall 2014, junior design students beginning their capstone experience created cmaps on the focus question: "What is sustainability?" Figure 2 shows an example of a student concept map. Structure of student knowledge was analyzed using the traditional cmap scoring method, while students' depth and breadth of sustainability knowledge represented in the content of cmaps was analyzed using word clouds, a strategy used by others for content analysis. ${ }^{39}$ 
From student concept maps, the social dimension demonstrated the greatest diversity of terms amongst the four categories (21 distinct concepts versus 16 for environment), although environmental concepts were included with greater frequency (30\% versus $27 \%$ for social). ${ }^{39}$ Interestingly, the students often distinguished between individual and community dimensions of the social pillar. Prior research on students' conceptual understanding of sustainability has overwhelmingly suggested that students emphasize the environmental dimension of sustainability, while largley neglecting social aspects (e.g., Watson et al. ${ }^{40}$ ). The "equity" dimension of social sustainability remains a weak area for students' conceptualizations and applications of sustainability knowledge, and the content of cmaps in this study did not indicate otherwise. The economic dimension was least well represented, both in terms of number of concepts within that category (six distinct concepts) and frequency (12\% of all concepts). ${ }^{39}$ Perhaps the integration of sustainability content into the unique sequence of design courses contributed to students' awareness of social aspects of sustainability. It is important to note that the majority of students participated in a client-based sophomore design project and are exposed to identifying stakeholder needs and impacts over a project's lifecycle during that course experience (see catalyst study: The Self-knowledge that Informs Decision Making and Problem Solving).

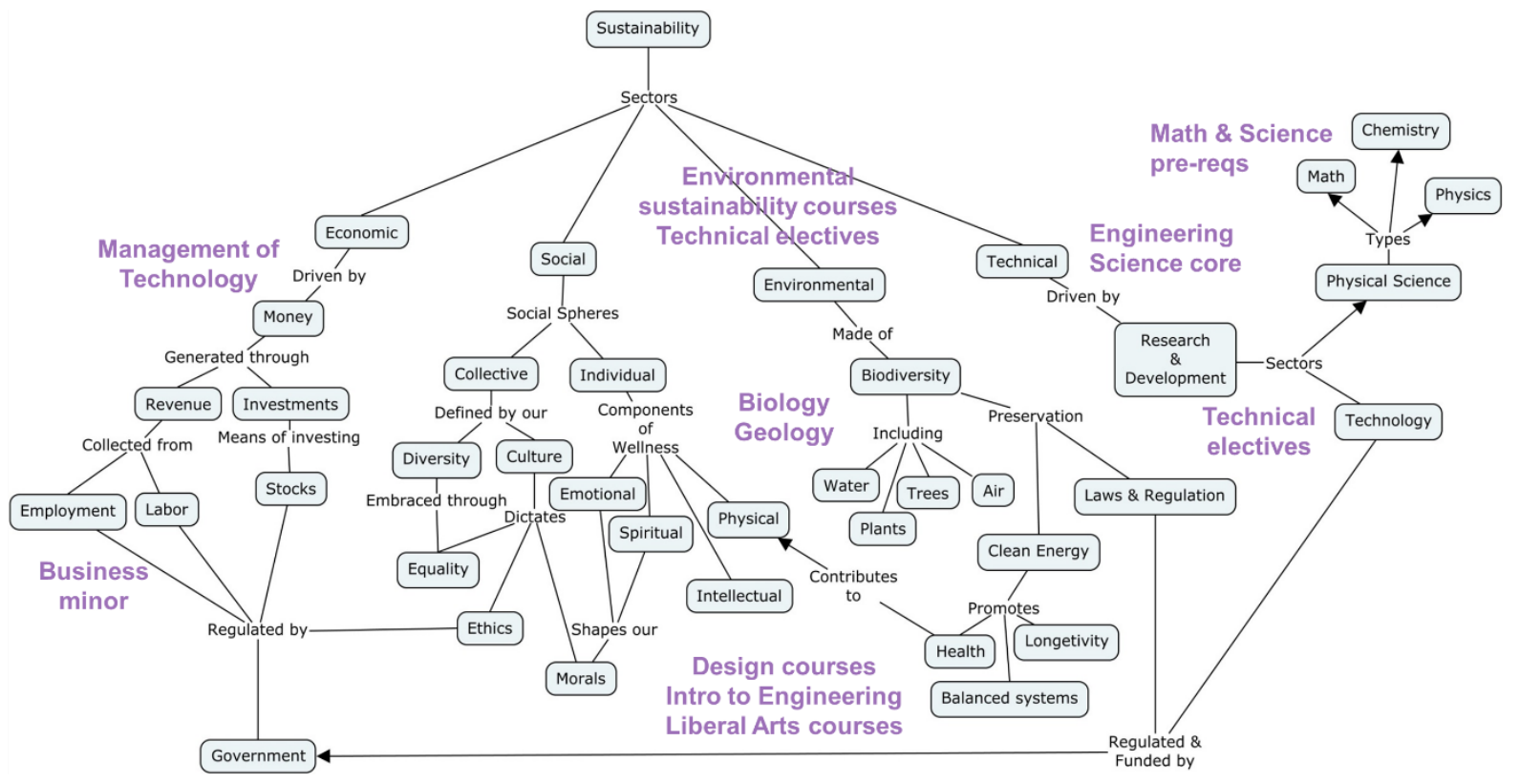

Figure 2: Example Student Concept Map of "What is Sustainability?" with purple text indicating typical courses where students would learn the concepts

In addition to the concept maps, junior design students also completed the 50-item Sustainable Personality survey, although not using PersonalityPad.org as described previously. Rather, students rated the survey items twice - first to describe their "real self" and second to describe their "ideal self." Given that the sustainability survey was administered in two different ways (ideal vs. real self), differences between responses on the same item would indicate dissonance between the ideal self and an individual's real behaviors. Although there were some negative scores in the data, the mean difference scores were all positive indicating that, on average, 
students responded with higher agreement to the ideal items than the real items. Based on the mean difference between ideal and real, students' reported the greatest dissonance (at least 1.00) in the following items.

- "I am a person who talks to my friends and family about the characteristics and qualities of our relationship." (Social)

- "I am a person who expresses myself with appropriate warm physical contact with friends." (Social)

- "I am a person who actively addresses health concerns." (Health)

- "I am a person who experiences physical discomfort caused by stress and anxiety." (Health)

- "I am a person who actively pursues good eating habits, including avoiding fast foods." (Health)

- "I am a person who is careful to get the amount of sleep I need." (Health)

- "I am a person who frequently experiences significant emotional stress in my life." (Emotional)

In addition to analyzing sources of student dissonance, we also explored the validity of the survey instrument when applied to engineering students.

Based on the results of factor analysis, the survey instrument was revised to include 36 items (versus the original 50), with six to eight items in each of the five categories: economic, social, intellectual, emotional, and health. In Fall 2015, the refined survey instrument was administered to engineering students enrolled in the introductory and design classes. For this iteration of the survey, students responded to the items twice: first, to reflect their "real self" behaviors and second, to reflect what is valued by an "ideal engineer." In addition, sophomore students responded to a prompt concerning the values of an ideal engineer and areas in which they could change behaviors to better align with those values. Junior students were asked to reflect on their survey responses and develop a personal "change plan" to address an area in which their real self differed from an ideal engineer. Preliminary analysis of 241 responses shows dissonance between real self and ideal engineer for each category. The following items indicated the greatest difference between real and ideal.

- "I am a person who talks with others about issues that are important to our society." (Social)

- "I am a person who experiences physical discomfort caused by stress and anxiety." (Health)

- "I am a person who eats a lot of processed foods, like fast food." (Health)

- "I am a person who is careful to get the amount of sleep I need." (Health)

Anecdotal evidence indicates that most junior students in the test sample identified one or more areas of dissonance from their responses to the real self and ideal engineer surveys and developed an appropriate change plan for the remaining five to six weeks of the semester. Analysis of the survey responses and written essays is on-going, along with factor analysis and other methods to determine survey validity; results of both will be reported in future publications. 


\section{Discussion}

Our research across disciplines and, as well, our studies with different objectives has resulted in some similar results. First, it seems clear that creating cognitive dissonance related to values and behaviors among our students is effective. One clear consistency among our results in all our studies is our students reporting individual behavior change based on wanting to align their behaviors with their often well-stated values. While we have our own suspicions concerning self-report data, our subjects' responses are consistent across all our studies. Our studies using cognitive dissonance related to values and behaviors have included nearly one thousand students.

A second, and related, result is that this methodology appears quite clearly to be transferrable to different disciplines. Our catalyst studies used this methodology in the following disciplines: engineering, science and technology, English, communications, and psychology. The results were fairly consistent, differing only in type of change reported.

Our third consistency is related to academic level. Catalyst and case studies have involved not only students across disciplines but also across academic levels, from first-year students to senior-level students. While upper-class students reported slightly greater degrees of change, this difference is too small to be considered significant. At this point, we have assumed that academic level (and academic discipline) is of little concern when designing future studies or recommending the methodology to others.

The potential to transfer our pedagogical approach across disciplines and grade levels is powerful and is not dependent on other course content. In one study, results of samples between a class related to intentional self-development and a class completely unrelated to the topic were compared. 'While the class related to self-development had "better" results, the class unrelated to self-development had significant results, even though the application was not tied to class material. Here we find that the usefulness of our application strategies is effective, even in situations in which the topic is largely foreign to the student sample. This area is, perhaps, the one most worthwhile for exploring because of its promise of being effective across disciplines as well as the little time it takes to produce noticeable results in students.

We believe that participant reflection is at the center of these changes, regardless of the specific changes being attempted or the discipline in which the studies occur. It is clear that many students are bothered by their values and behaviors being misaligned, regardless of the specific value being addressed. This may be due to students' believing that their own integrity is at stake here, or that the authenticity of their expressions may be in question. Why students do not experience this often obvious cognitive dissonance at other times — or without our assistance - is unclear to us. Quite clearly, we are putting students into situations in which they have to reflect on themselves, a practice that often results in greater self-awareness and understanding of individual responsibility, regardless of the setting.

Measuring educational outcomes using behaviors is the central objective of our overall efforts. We believe that student behaviors, more than content knowledge or attitudes, measure learning more thoroughly and effectively (especially long-term). The fact that successful behaviors may 
tend to become personality characteristics drives our research and experimentation. Our research indicates that students' desire for integrity and individual value consistency, often taught to them in childhood, as well as revered (if not often practiced) in American culture, tend to move them to align their values and behaviors.

All societal change begins with individual change. One cannot do for a community what one cannot do for one's self. The topic of individual sustainability is a controversial one, as students often appear to be unable to align their demonstrated behaviors with their admirable values related to sustainability. Individual behavior creates the foundation for action in social, economic, and environmental sustainability and potentially guides our ability to work with one another to solve problems and make life-affirming decisions. In short, it is a matter of aligning our day-to-day behaviors with our well-stated values that will result in greater sustainable community action. We can hardly understand sustainability on a global level if we do not understand it within ourselves.

Unfortunately, in terms of how universities focus their curricula, these results are disturbing. That such important topics would find little or no place in a university curriculum illustrates an educational system dramatically misguided.

\section{Future Work}

The work reported here is in its relative infancy, despite having been the subject of nearly ten studies and almost as many publications. Our future work will be characterized especially by moving away from self-report, a task considerably more difficult than it might appear. While students seem to respond honestly to the survey instruments and reflections, given the academically low-stakes assignments, it is unclear whether they fully achieve (or sustain) the change that they report. Intentional changes in personality may rarely be reported honestly by individuals. We do have an online multisource feedback tool, PersonalityPad.org (PersonalityPad.org V2.0 will be released Summer 2016), that will help meet this need. As for other mixed methods of reporting, we will need to tailor our projects more specifically to our assessment tools and strategies.

Some other topics for later studies, perhaps, are the applicability of our methodology in workplace settings. We find this idea enticing and believe there is no reason our results would differ much from our academic studies. Will professional engineers, scientists, etc. change their behaviors when confronted with dissonance between stated values and behaviors? As well, we are interested in broader transferability of the studies to demonstrate that the cognitive dissonance methods and processes are applicable at other universities. As part of the grant's evaluation plan, we intend to have partners at other universities (representing different institutional settings and engineering disciplines) administer the Sustainable Personality survey and reflection through PersonalityPad.org V2.0. The goal is to demonstrate that introducing dissonance with the Sustainable Personality survey and encouraging self-directed change is an effective approach in different educational contexts. 


\section{Acknowledgements}

The authors would like to acknowledge the support of the National Science Foundation through award \#1158728. Any opinions, findings and conclusions, or recommendations expressed in this material are those of the author and do not necessarily reflect the views of the National Science Foundation.

\section{References}

1. Pappas JB, Pappas EC. The Sustainable Personality: Values and Behaviors in Individual Sustainability. International Journal of Higher Education. 2015;4(1):12-21.

2. Pappas E, Pappas J. A Behavioral Approach to Building Cognitive Foundations for Effective Thought and Action. Innovative Higher Education. 2011;36(5):359-372.

3. Maslow A. Toward a Psychology of Being. New York, NY: Van Nostrand; 1968.

4. $\quad$ Rogers C. A Way of Being. New York, NY: Houghton Mifflin; 1980.

5. Adams JL. Conceptual Blockbusting. New York, NY: Perseus Books; 2001.

6. Petroski H. To Engineer is Human. New York, NY: Vintage Books; 1992.

7. Bigda-Peyton F. When drives are dangerous: Drive theory and resource overconsumption. Modern Psychoanalysis. 2004;29(2):251-270.

8. Rogers CR. Client-centered Therapy: Its Current Practices, Implications, and Theory. Boston, MA: Houghton-Mifflin; 1951.

9. Brandtstädter J, ed The Self in Action: Cultural, Biosocial, and Ontogenetic Bases of Intentional Selfdevelopment. Thousand Oaks, CA: Sage; 1999. Brandtstädter J, Lerner R, eds. Action and Selfdevelopment: Theory and Research through the Lifespan.

10. Baltes PB, Baltes MM, eds. Psychological perspectives on successful aging: The model of selective optimization with compensation. New York, NY: Cambridge University Press; 1990. Baltes PB, Baltes MM, eds. Successful Aging Perspectives from the Behavioral Sciences.

11. Freund AM, Li Z, Baltes P, eds. The Role of Selection, Optimization, and Compensation in Successful Aging. Thousand Oaks, CA: Sage; 1999. Brandtstädter J, Lerner R, eds. Action and Self-development: Theory and Research through the Lifespan.

12. Brandtstädter J, ed Action Perspectives on Human Development. 5th ed. New York, NY: Wiley: Wiley; 1998. Damon W, Lerner RM, eds. Theoretical models of human development No. 1.

13. Rotter JB. Generalized Expectancies for Internal Versus External Control of Reinforcements. Psychological Monographs. 1966;80(1):1-28.

14. Schultz R, Heckhausen J. A Life Span Model of Successful Aging. American Psychologist. 1996;51(2):702-714.

15. Morf C, Horvath S, eds. Self-regulation Processes and Their Signatures: Dynamics of the Self-system. Malden, MA: Wiley- Blackwell; 2010. Hoyle R, ed. Handbook of Personality and Self-regulation.

16. Gestsdottir S, Lerner RM. Positive Development in Adolescence: The Sevelopment and Role of Intentional Self-regulation. Human Development. 2008;51(3):202-224.

17. Baltes PB. On the Incomplete Architecture of Human Ontology: Selection, Optimization, and Compensation as Foundation of Developmental Theory. American Psychologist. 1997;52(1):366-380.

18. Rogers C. Freedom to Learn. Columbus, OH: Merrill; 1969.

19. Prochaska JO, Velicer WF. The Transtheoretical Model of Health Behavior Change. American Journal of Health Promotion. 1997;12(1):38-48.

20. Pappas E. A Behavioral Approach to Building Cognitive Foundations for Effective Thought and Action in a Freshman Critical Thinking Course. 41st ASEE/IEEE Frontiers in Education Conference; 12-15 Oct. 2011, 2011; Rapid City, South Dakota.

21. Pappas E. Creative Problem Solving in Engineering Design. American Society of Engineering Education (ASEE) Southeastern Section Conference; 2002; University of Florida, Gainesville. 
22. Pappas E. Teaching and Thinking and Problem Solving in the University Curriculum: A Rationale. American Society for Engineering Education (ASEE) Southeastern Section Conference; 2004; Auburn, Alabama.

23. Festinger L. A Theory of Cognitive Dissonance. New York: Row, Peterson \& Co.; 1957.

24. Brehm JW, Cohen AR. Explorations in Cognitive Dissonance. New York, NY: Wiley; 1962.

25. Wicklund RA, Brehm JW. Perspectives on Cognitive Dissonance. Hillsdale, N.J.: Lawrence Erlbaum Associates; 1976.

26. E. H-J, H. P, 25:69-78 VKBASP. The Dissonance-inducing Effects of an Inconsistency between Experienced Empathy and Knowledge of Past Failures to Help: Support for the Action-based Model of Dissonance. Basic and Applied Social Psychology. 2003;25(1):69-78.

27. Monin B, Norton MI, Cooper J, Hopg MA. Reacting to an Assumed Situation vs. Conforming to an Assumed Reaction: The Role of Perceived Speaker Attitude in Vicarious Dissonance. Group Processes \& Intergroup Relations. 2004;7(3):207-220.

28. Norton MI, Monin B, Cooper J, Hogg MA. Vicarious Dissonance: Attitude Change from the Inconsistency of Others. 2003;85(1):47-62.

29. Barrella E, Watson. MK. Comparing Outcomes of Horizontal and Vertical Integration of Sustainability Content into Engineering Curricula Using Concept Maps. 7th International Conference on Engineering Education for Sustainable Development; 6-9 June 2015, 2015; Vancouver, Canada.

30. Tulving E, ed Episodic and Semantic Memory. Oxford, England: Academic Press; 1972. Donaldson ETaW, ed. Organization of Memory.

31. Boyd EM, Fales AW. Reflective Learning: Key to Learning from Experience. Journal of Humanistic Psychology. 1983;23(2):99-117.

32. Atkins S, Murphy K. Reflection: a review of literature. Journal of Advanced Nursing. 1993;18(8):11881192.

33. Nagel RL. Exploration of Individual Values as Related to Project Teams in a Sophomore Engineering Design Course Sequence. Frontiers of Engineering Education; 2012; Irvine, CA.

34. Pappas EC. Individual sustainability: Preliminary research. 2013 IEEE Frontiers in Education Conference (FIE); Oct. 23 - 26, 2013, 2013; Oklahoma City, OK.

35. Nagel RL, Pappas EC, Swain M, Hazard GA. Exploration of Engineering Students' Values with Respect to Behaviors in Group Work. International Journal of Higher Education. 2014;4(2):181-197.

36. Nagel RL, Pappas EC, Hazard GA, Swain M. Understanding How Students' Value the Behaviors of Individuals in Engineering Teams. 121st ASEE Annual Conference \& Exposition; 2014; Indianapolis, IN.

37. Benton M, Pappas J, Pappas E. WordPress + Qualtrics: A Plugin Supporting Research and New Pedagogy to Develop Personal Sustainability via $360^{\circ}$ Evaluation. AMCIS 2011: 17th Americas Conference on Information Systems; 2011; Detroit, MI.

38. Pappas E, Lynch R. Individual Sustainability: Teaching Intentional Self-development in Large Classes. Conference on Teaching Large Classes: Virginia Tech, Blacksburg, Virginia; 2015.

39. Huynh N, Caicedo JM, Pierce CE, Gantt JW. Combining In-Class Design Problems and EFFECTs to Stimulate Critical Thinking Skills. ASEE Annual Conference and Exposition; 2013; Atlanta, GA.

40. Watson MK, J.G. P, C. N, M.O. R. Use of Concept Maps to Assess Student Sustainability Knowledge. ASEE Annual Conference and Exposition; 2014; Indianapolis, IN. 